\title{
Enhancement in Fabric Quality by Optimizing the Dyeing Process Parameters Using Response Surface Methodology
}

\author{
${ }^{1 *}$ Kamal Ojha, ${ }^{2}$ Vishal Achwal \\ Discipline of Mechanical Engineering Truba College of Engineering and Technology, Indore (M.P) India
}

\begin{abstract}
The aim of this paper is to report the experimental work carried out to enhance the fabric (single jersey) quality of in terms of fabric GSM and fabric width in fabric dyeing process. Twenty experiments are planned using RSM by varying the three input parameters namely fabric heating temperature, peroxide dosing 1 and peroxide dosing 2 at five levels. The detailed examination of the results and testing of the varying input parameters for their significance at $95 \%$ confidence interval using ANOVA technique by Design expert version 8 of stat ease Inc. is performed to calculate the percentage contribution of the input parameters and their interactions on the responses. From the results of the response surface model it was found that the optimized parametric combination for obtaining the required quality of fabric i.e. fabric GSM 150 and fabric width $180 \mathrm{~cm}$; are very obtained by using the identified parametric combinations namely fabric heating temperature as $90^{\circ} \mathrm{C}$, peroxide dosing time 1 as 5 minutes and peroxide dosing time 2 as 7.5 minutes.
\end{abstract}

\section{Introduction}

Textile materials can be dyed using batch, continuous or semi-continuous processes. The type of process used depends on several things including type of material fibre, yarn, fabric, fabric construction, and garment), generic type of fibre, size of dye lots and quality requirements in the dyed fabric. Machinery for dyeing must be resistant to attack by acids, bases, other auxiliary chemicals and dyes. Batch processes are the most common method used to dye textile materials. Batch dyeing is sometimes called exhaust dyeing because the dye is gradually transferred from a relatively large volume dye bath to the material being dyed over a relatively long period of time. The dye is said to exhaust -from the dye bath to the substrate. Textile substrates can be dyed in batch processes in almost any stage of their assembly into a textile product including fiber, yarn, fabric or garment. Generally, flexibility in color selection is better and cost of dyeing is lower the closer dye application is to the end of the manufacturing process for a textile product. The three general types of batch dyeing machines are those in which the fabric is circulated, those in which the dye bath is circulated while the material being dyed is stationary, and those in which both the bath and material are circulated. Fabrics and garments are commonly dyed in machines in which the fabric is circulated. The formulation is in turn agitated by movement of the material being dyed. Fiber, yarn and fabric can all be dyed in machines which hold the material stationary and circulate the dye bath. Jet dyeing is the best example of a machine that circulates both the fabric and the dye bath. Jet dye machines are excellent for knit fabrics, but woven fabrics can also be dyed using jet machines.

Many researchers have shown their interests in the development of various fabric dyeing processes. In the most recent work Murugesh et al. (2013) reported the influence of wet processing on properties of single jersey knitted fabrics. The physical, dimensional and dyeing properties of the single jersey knitted fabrics were investigated after different wet processing stages and sequences. For this purpose, 2/40's, 100\%, organic cotton single jersey greige knitted fabric was developed and concluded that the dyeing behavior of Ready to stitch (RTS) fabric show that fabric dyed with mercerized ready for dyeing (RFD) fabric has greater colour strength compared to RTS fabric dyed with scoured RFD fabric. Saha et al. (2013) had done a comparative study on garments dyeing process and fabric dyeing process on various parameters. They compared the garments dyeing and fabric dyeing process by using direct dye and reactive dye and found that on changing $\mathrm{pH}$ in polyester fabric different types of shade are achieved. Syed et al. (2013) had done a comparative analysis of conventional and ultrasonic exhaust dyeing method for dyeing of organic cotton fabric. They reported dyeing with ultrasonic technique at $60^{\circ} \mathrm{C}$ for 30 minutes gives colour strength value almost equal to the conventional recommended dyeing method. Further, they concluded that the dyeing of organic material using ultrasonic exhaust method saves energy and time. Use of reactive dye for dyeing the $100 \%$ cotton knit fabrics is done by Chowdhury et al. (2009). Their study was identified that precision setup of cycle time, run-time, dosing time and temperature gradient can improve meter-to-meter variation from $66 \%-86 \%$; their study considers the factors namely water hardness, dyes combination and dyes leveling properties were optimum. Tepparin et al. (2012) during their research work they studied and reported that the extraction of the natural dye from two different types of tamarind seed viz. sour-tamarind seed (TF) and sweet-tamarind seed (TO). The extracted dye solutions were prepared into a powder form and subsequently used for dyeing cotton and Bombyx Mori silk and Eri silk 
fabrics. From the experiment, the TF dye powder was easier soluble in water and could render a higher color strength than the TO dye powder. It was found for the tamarind-seed dyes that they could better exhausted on the silk fabrics than the cotton. The Effect of reactive dyeing and cellulase treatment on the pilling properties of cotton knitted fabric was studied by Kan and law (2012). Their study was aimed to study the relationship of reactive dyes and cellulase treatment on the pilling properties of cotton knitted fabric. Two commercial reactive dyes with different chemical structures were used. The dyeing and cellulase application were conducted in different. Experimental results revealed that the pilling results were varied depending on the different stages of applying reactive dyeing and cellulase treatment. One bath method dyeing of polyester/cotton blend fabric was experimentally explored by Najafi et al. (2009) during their research work their study was focused on improving the adhesion of chitin to the surface of polyester/cotton fibers; for this pre-treatment using $\mathrm{NaOH}$ solutions was performed. They reported that the colour strength of the dyed samples increased with the increased deposition of chitin on the fabric.

\section{Details of Experimentation}

In the present research work new outline of investigation using response surface methodology (RSM), central composite design technique is planned to investigate the influence of fabric heating and peroxide dosing time for improving the fabric width and fabric GSM. A Central Composite Design part of RSM is used to design the experimental run at five levels by changing the accompanying three parameters in particular, fabric heating (T), peroxide dosing time (PD1) and peroxide dosing time (PD2), while keeping the other affecting process parameters as constant in contrast with the past literatures. Table 1, Shows the levels of input parameters and fixed parameters. These values are chosen on the basis of past works and experimentations constraints.

The designs of experiments are designed with the help of a statistical software "Design expert 8 " by Stat-Ease Inc. A rotatable central composite design from response surface methodology (RSM) is used for design the experimental run. Three main process parameters are chosen as input (namely Fabric heating temperature, Peroxide dosing time 1, Peroxide dosing time 2 while keeping the other process affecting parameters as constant due to machine restrictions. A lot of $1 \mathrm{~kg}$ of raw material (cotton fabric) is chosen as a material considering the machine feasibility. Each experimental run required 60 minutes to gives the selected output (namely Fabric width and Fabric GSM). The measurements for fabric width are taken with the precise and sophisticated measuring instruments by Mitutoya Japan, while a weighing machine is used to measure the GSM of the fabric, weighing of the fabric GSM is taken in an insulated environment to avoid errors. Random samples of fabric are chosen for measuring the fabric GSM from a lot.

Table 1 levels and values of input parameters and fixed parameters.

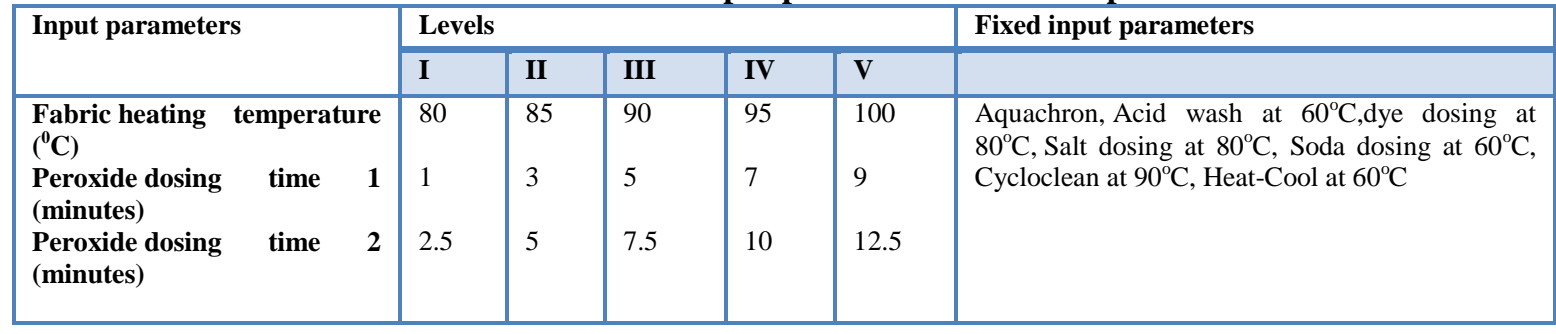

\section{Results and Discussion}

On detailed examinations for the results evaluated for all 20 experiments from table 2 . It can be observed from the obtained results that the 6 experiments are performed at parametric combination for obtaining the required fabric width is fabric heating temperature as $90^{\circ} \mathrm{C}$, peroxide dosing time 1 as 5 minutes and peroxide dosing time 2 as 7.5 minutes. Further the obtained result shows that these parametric combinations the average values of fabric GSM and width are 150.05 and $180.28 \mathrm{~cm}$ which are very real and near to the required value of fabric GSM and width i.e. 150 and $180 \mathrm{~cm}$.

Table 2 presents the results of all 20 experiments, by using these results a regression analysis was used to develop the response surface model for the prediction of the fabric width and fabric GSM. The significance of the developed models was tested at 95\% confidence interval using the ANOVA system, and the outcomes of quadratic form response surface model fitting as ANOVA are given in Tables 3 and 4. The significance tests for the regression models, the test for significance on individual model terms and the lack of-fit test are performed utilizing the statistical Design-Expert 8.0 software package. The step-wise regression technique is utilized, which eliminates the insignificant model terms. The model $\mathrm{F}$ value suggests that the model is significant. The esteems of "Probability more than F" in table 3 and 4 for the term of models under 0.05 (i.e., a $=0.05$, or $95 \%$ confidence level) demonstrates that the created models are acknowledged to be statistically significant at $95 \%$ 
Enhancement in Fabric Quality by Optimizing the Dyeing Process Parameters Using Response

confidence level, which is desirable as it exhibits that the terms in the model have a significance on the responses.

Table 2 Comprehensive results of all 20 experiments with the levels of input parameters

\begin{tabular}{|c|c|c|c|c|c|}
\hline \multirow{2}{*}{$\begin{array}{l}\text { Standard } \\
\text { order }\end{array}$} & \multicolumn{3}{|l|}{ Input parameters } & \multicolumn{2}{|l|}{ Responses } \\
\hline & $\begin{array}{l}\text { Fabric Heating } \\
\text { temperature }\left({ }^{0} \mathrm{C}\right)\end{array}$ & $\begin{array}{l}\text { Peroxide } \\
\text { dosing time } \\
1 \text { (minutes) }\end{array}$ & $\begin{array}{l}\text { Peroxide } \\
\text { dosing time } \\
2 \text { (minutes) }\end{array}$ & $\begin{array}{l}\text { Fabric } \\
\text { Width }(\mathrm{cm})\end{array}$ & Fabric GSM \\
\hline 1 & 85 & 3 & 5 & 168.70 & 161.20 \\
\hline 2 & 95 & 3 & 5 & 173.30 & 155.20 \\
\hline 3 & 85 & 7 & 5 & 169.10 & 158.34 \\
\hline 4 & 95 & 7 & 5 & 174.80 & 153.20 \\
\hline 5 & 85 & 3 & 10 & 169.56 & 154.20 \\
\hline 6 & 95 & 3 & 10 & 172.00 & 152.00 \\
\hline 7 & 85 & 7 & 10 & 167.23 & 159.20 \\
\hline 8 & 95 & 7 & 10 & 174.00 & 154.32 \\
\hline 9 & 80 & 5 & 7.5 & 164.00 & 162.00 \\
\hline 10 & 100 & 5 & 7.5 & 173.00 & 156.45 \\
\hline 11 & 90 & 1 & 7.5 & 174.87 & 155.50 \\
\hline 12 & 90 & 9 & 7.5 & 176.00 & 157.00 \\
\hline 13 & 90 & 5 & 2.5 & 173.00 & 159.00 \\
\hline 14 & 90 & 5 & 12.5 & 168.00 & 160.00 \\
\hline 15 & 90 & 5 & 7.5 & 180.20 & 150.20 \\
\hline 16 & 90 & 5 & 7.5 & 180.33 & 150.34 \\
\hline 17 & 90 & 5 & 7.5 & 180.13 & 150.00 \\
\hline 18 & 90 & 5 & 7.5 & 180.19 & 150.05 \\
\hline 19 & 90 & 5 & 7.5 & 180.50 & 150.02 \\
\hline 20 & 90 & 5 & 7.5 & 180.35 & 150.03 \\
\hline
\end{tabular}

Table 3 ANOVA results for Fabric GSM

\begin{tabular}{|l|l|l|l|l|l|l|l|}
\hline Source & $\begin{array}{l}\text { Sum of } \\
\text { Squares }\end{array}$ & df & $\begin{array}{l}\text { Mean } \\
\text { Square }\end{array}$ & F ratio & $\begin{array}{l}\text { p- } \\
\text { value } \\
\text { Prob> } \\
\text { F }\end{array}$ & $\begin{array}{l}\text { P } \\
(\%)\end{array}$ & $\begin{array}{l}\text { Significant/Insignificant } \\
\text { at 95\% CI }\end{array}$ \\
\hline Model & 308.7481 & 9 & 34.30534 & 29.07396 & $\begin{array}{l}< \\
0.0001\end{array}$ & 96.31 & Very significant \\
\hline $\begin{array}{l}\text { A-Fabric } \\
\text { heat } \\
\text { temperature }\end{array}$ & 53.7289 & 1 & 53.7289 & 45.53553 & $<$ & 16.76 & Very significant \\
\hline $\begin{array}{l}\text { B-Peroxide } \\
\text { dosing time 1 }\end{array}$ & 1.863225 & 1 & 1.863225 & 1.579093 & 0.2375 & 0.58 & Insignificant \\
\hline $\begin{array}{l}\text { C-peroxide } \\
\text { dosing time 2 }\end{array}$ & 2.418025 & 1 & 2.418025 & 2.049289 & 0.1828 & 0.75 & Insignificant \\
\hline AB & 0.41405 & 1 & 0.41405 & 0.35091 & 0.5668 & 0.12 & Insignificant \\
\hline AC & 2.06045 & 1 & 2.06045 & 1.746242 & 0.2158 & 0.64 & Insignificant \\
\hline BC & 18.54405 & 1 & 18.54405 & 15.71618 & 0.0027 & 0.57 & significant \\
\hline $\mathbf{A}^{\wedge 2}$ & 127.3989 & 1 & 127.3989 & 107.9712 & $<$ & 39.61 & Very significant \\
\hline B^2 & 57.11961 & 1 & 57.11961 & 48.40917 & $<$ & 17.81 & Very significant \\
\hline C^2 & 135.2998 & 1 & 135.2998 & 114.6673 & $<$ & 42.20 & Very significant \\
\hline
\end{tabular}


Enhancement in Fabric Quality by Optimizing the Dyeing Process Parameters Using Response

\begin{tabular}{|l|l|l|l|l|l|l|l|}
\hline Residual & 11.79934 & 10 & 1.179934 & & & & \\
\hline Lack of Fit & 11.70871 & 5 & 0.341743 & 2.2056 & $\begin{array}{l}< \\
0.451\end{array}$ & & Insignificant \\
\hline Pure Error & 0.090621 & 5 & 0.018124 & & & & \\
\hline $\begin{array}{l}\text { Corrected } \\
\text { Total }\end{array}$ & 320.5474 & 19 & & & & & \\
\hline
\end{tabular}

Table 4 ANOVA results for Fabric Width

\begin{tabular}{|l|l|l|l|l|l|l|l|}
\hline Source & $\begin{array}{l}\text { Sum of } \\
\text { Squares }\end{array}$ & $\begin{array}{l}\text { Degree } \\
\text { of } \\
\text { freedom }\end{array}$ & $\begin{array}{l}\text { Mean } \\
\text { Square }\end{array}$ & Value F & $\begin{array}{l}\text { p-value } \\
\text { Prob> F }\end{array}$ & P \% & $\begin{array}{l}\text { Significant I } \\
\text { Insignificant at } \\
\text { 95\% CI }\end{array}$ \\
\hline Model & 468.5972 & 9 & 52.06636 & 15.36641 & $<0.0001$ & 93.25 & Very significant \\
\hline $\begin{array}{l}\text { A-Fabric heat } \\
\text { temperature }\end{array}$ & 87.93751 & 1 & 87.93751 & 25.95312 & 0.0005 & 17.5 & Significant \\
\hline $\begin{array}{l}\text { B-Peroxide } \\
\text { dosing time 1 }\end{array}$ & 0.916806 & 1 & 0.916806 & 0.270578 & 0.6143 & 0.18 & Insignificant \\
\hline $\begin{array}{l}\text { C-peroxide } \\
\text { dosing time 2 }\end{array}$ & 10.74201 & 1 & 10.74201 & 3.170303 & 0.1053 & 2.13 & Insignificant \\
\hline AB & 3.685613 & 1 & 3.685613 & 1.08774 & 0.3215 & 0.73 & Insignificant \\
\hline AC & 0.148512 & 1 & 0.148512 & 0.043831 & 0.8384 & 0.02 & Insignificant \\
\hline BC & 0.621612 & 1 & 0.621612 & 0.183457 & 0.6775 & 0.12 & Insignificant \\
\hline $\mathbf{A}^{\wedge 2}$ & 254.5091 & 1 & 254.5091 & 75.11361 & $<0.0001$ & 50.65 & Very significant \\
\hline B^2 & 52.70555 & 1 & 52.70555 & 15.55506 & 0.0028 & 10.48 & Very significant \\
\hline $\mathbf{C}^{\wedge 2}$ & 180.8005 & 1 & 180.8005 & 53.3599 & $<0.0001$ & 35.98 & Very significant \\
\hline Residual & 33.88322 & 10 & 3.388322 & & & & \\
\hline Lack of Fit & 8.9079048 & 5 & 8.9079048 & 64.3834 & 0.54 & & Insignificant \\
\hline Pure Error & 0.092733 & 5 & 0.018547 & & & & \\
\hline Corrected Total & 502.4804 & 19 & & & & & \\
\hline
\end{tabular}

Table 3-4 illustrates the ANOVA table for fabric GSM and fabric width and it can be seen that the Model F-value of 29.07 and 15.36 implies that the developed model is significant. There is only a $0.01 \%$ chance that the "Model F-Value" 29.07 and 15.36 will occur due to noise. For fabric GSM A, BC, $\mathrm{A}^{2}, \mathrm{~B}^{2}, \mathrm{C}^{2}$ are found to be having significant while for fabric width $\mathrm{A}, \mathrm{A}^{2}, \mathrm{~B}^{2}, \mathrm{C}^{2}$ are the significant model terms and having

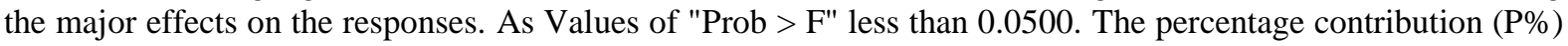
are calculated for all the input parameters using table 3 and it is evident that the calculated percentage contribution for Fabric GSM are fabric heating temperature is $16.76 \%$, square term of fabric heating temperature is $39.61 \%$, square term of peroxide dosing time 1 is $17.82 \%$ and square term of peroxide dosing time 2 is $42.20 \%$. Whereas for the fabric width the major contributors are fabric heating temperature as $17.5 \%$, sqaure term of fabric heating temperature as $50.65 \%$, square term of peroxide dosing time 1 as $10.48 \%$ and square term of peroxide dosing time 2 as $35.98 \%$.

The theoritical mathematical model developed using statistical software on the basis on ANOVA results for fabric GSM and fabric width using statistical software is presented in Eqn.1-2

$$
\begin{aligned}
\text { Fabric GSM }= & 150.05-1.83 A+0.34 B-0.39 C-0.23 A B+0.51 A C+1.52 B C+2.25 A^{2} \\
& +1.51 B^{2}+2.32 C^{2} \quad(1) \\
\text { Fabric Width }= & 179.81+2.34 \mathrm{~A}+0.24-0.82 \mathrm{C}+0.68 \mathrm{AB}-0.14 \mathrm{AC}-0.28 \mathrm{~B} C-3.18 \mathrm{~A}^{2} \\
& -1.45 \mathrm{~B}^{2}-2.68 \mathrm{C}^{2} \quad(2)
\end{aligned}
$$

From the obtained experimental results in table 1 and from Figure (1-3) it can be seen that the optimum parametric combination for obtaining the required fabric GSM and fabric width are fabric heating temperature as $90^{\circ} \mathrm{C}$, peroxide dosing time 1 as 5 minutes and peroxide dosing time 2 as 7.5 minutes. As the obtained results shows that the 6 experiments are performed at these parametric combinations and the average values of fabric GSM and width obtained at these levels are 150.05 GSM and $180.20 \mathrm{~cm}$ which is very much real and marginally equivalent to the required fabric GSM i.e., 150 GSM and $180 \mathrm{~cm}$. Further Figure 1-3 depicts the variation in fabric GSM and width with respect to the input parameters i.e., fabric heating temperature, peroxide dosing time 1 and peroxide dosing time 2 . Fig 1 shows that at temperature below $90^{\circ} \mathrm{C}$ and the average 
values of the fabric GSM are increasing and fabric width are decreasing while on at $90^{\circ} \mathrm{C}$ the average values are found to be very significant as their values matches with the requirements, further on increasing the temperature beyond $90^{\circ} \mathrm{C}$ the fabric GSM and fabric width both increases i.e., the results obtained below and beyond $90^{\circ} \mathrm{C}$ are not acceptable with the requirements. From (fig 2) it can be observed that the average values of the fabric GSM and fabric width follows the same trends as with fabric heating temperature i.e., at value of peroxide dosing time 1 lesser than 5 minutes and higher than 5 minutes the Fabric GSM and fabric width crumbles and not matching with the required standards. Similar trends can be seen from figure 3 i.e., the fabric GSM and width quality diminishes at peroxide dosing time lesser and higher than 7.5 minutes.

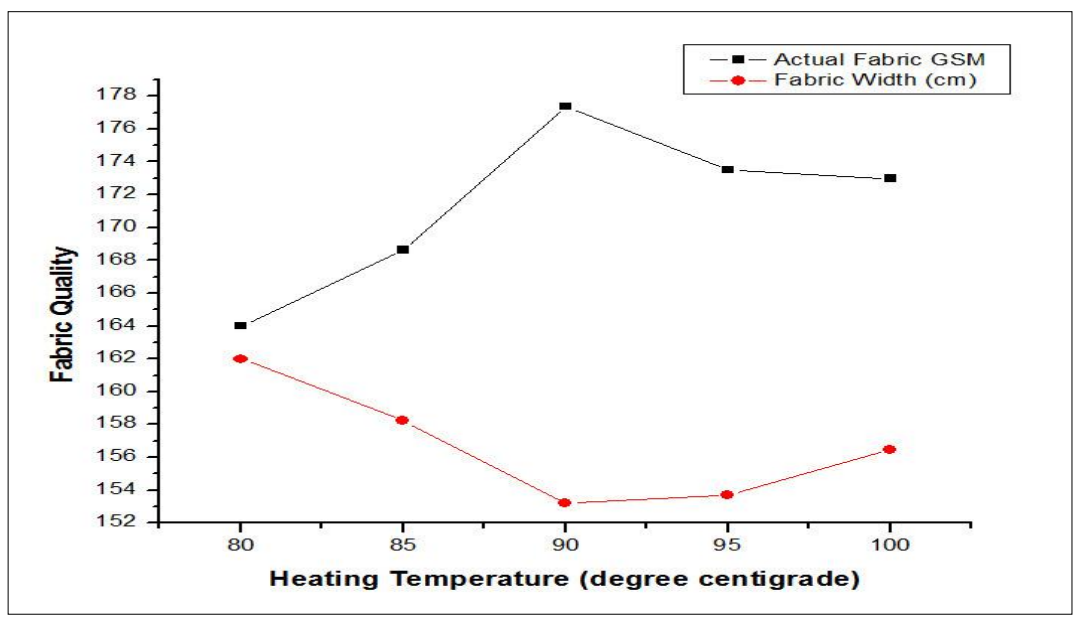

Fig 1 Effects of fabric heating temperature on GSM and width of the fabric

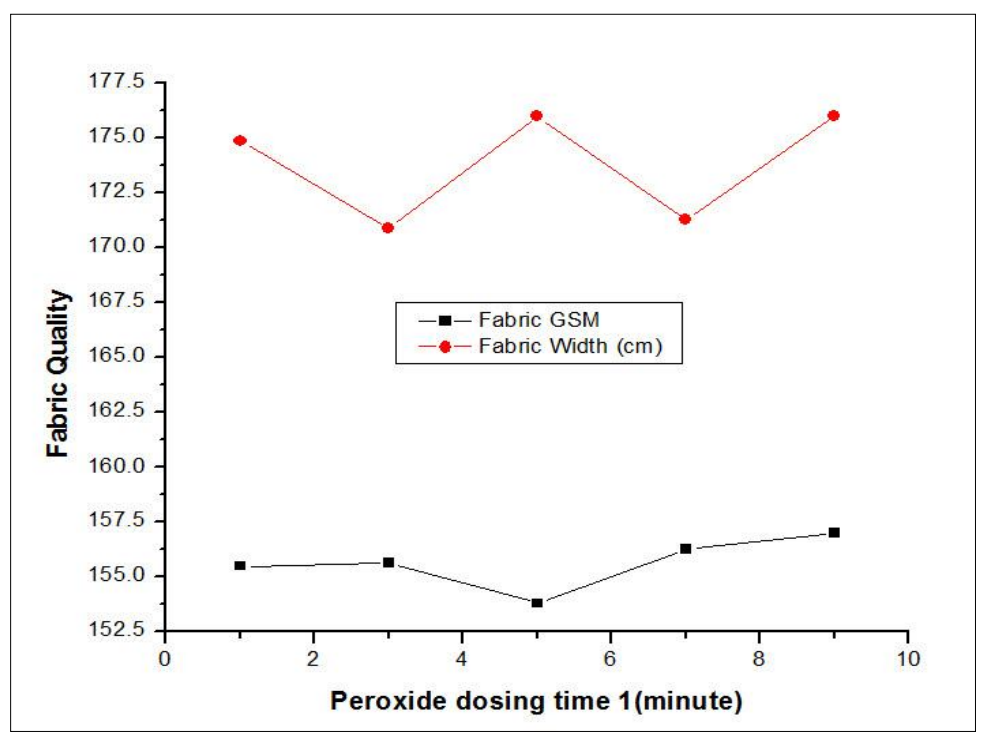

Fig 2 Effects of peroxide dosing 1 on GSM and width of the fabric 


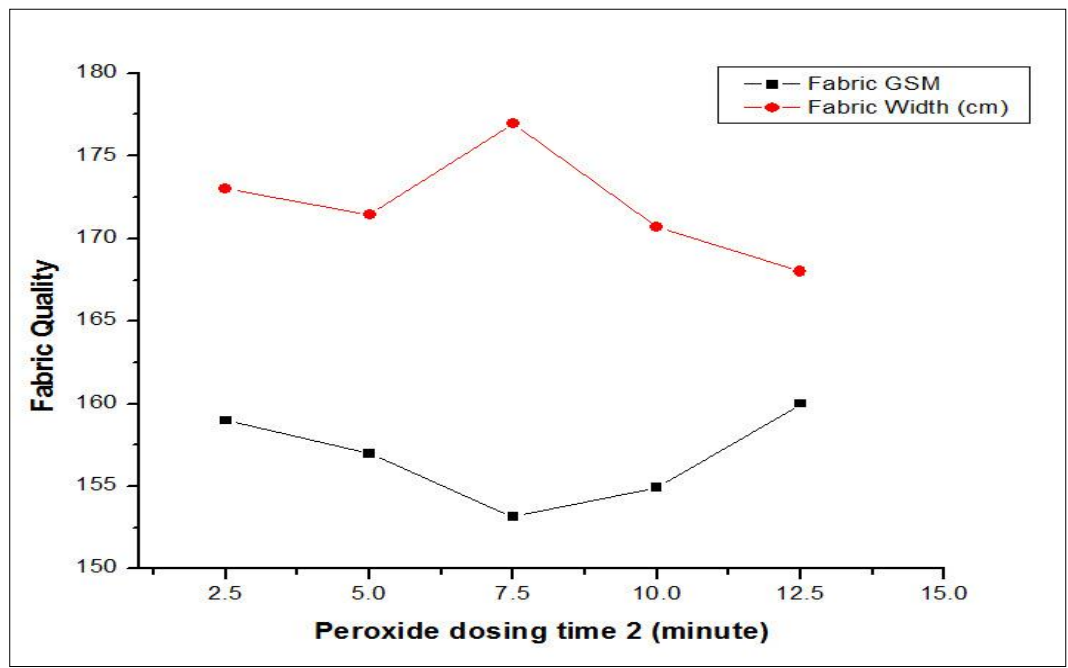

Fig 3 Effects of peroxide dosing 2on GSM and width of the fabric

The explanation for the obtained results can be summarized with the help of following points

1. Fabric heating temperature, peroxide dosing time 1 and peroxide dosing time 2 are having the major influence on the fabric GSM and fabric width.

2. It is evident that fabric heating is performed for better dilution of the colour dye for better shades in the fabric which in returns reflects in the better fabric quality.

3. it is evident that on heating the fabric lesser than $90^{\circ} \mathrm{C}$ the dilution and mixing of the coloring agents are not affective because of which the color dye uploads higher quantity of coloring agents on the fabric which adversely gives the higher GSM and lower width values of the fabric and affects the process, while on temperature higher than $90^{\circ} \mathrm{C}$ it is reported that the dilution of coloring agents is more due to which the fabric will absorb more liquid and pores of the fabric fill with the liquid coloring agents and gives higher GSM.

4. It is evident that peroxide dosing is used for mixing the coloring agents in liquid for dilution and it is observed from the obtained results that the peroxide dosing time 1 is found to be have best effects when its esteem reaches to 5 minutes while for peroxide doing time 2 found best at 7.5 minutes due to the fact that the peroxide dosing 1 is performed just after the heating of fabric in water and peroxide chemical mixes approximately $95 \%$ at $90^{\circ} \mathrm{C}$ at 5 minutes of processing time it is found by experimentations. It is evident that proper mixing of chemical agents i.e. peroxide in liquid at sufficient high temperature is necessary for achieving the better fabric quality.

5. In last the effects of peroxide dosing time 2 on fabric GSM and width can be understood with the fact that this process is performed after four different heating and cooling process including "Aquachron" in which the soft water is refilled in the dyeing machine and sludge's are drained. The final temperature of liquid in which fabric is poured after completing the intermediate operations was found nearly $77^{\circ} \mathrm{C}$ which in return takes longer processing time to mix the chemical agent i.e. peroxide as compared with the earlier dosing time, and from the experimentations it was found that the effective time observed for mixing the peroxide 2 is 7.5 minutes on which the obtained fabric GSM and width meets with the requirement.

\section{Conclusion}

The aim of the present investigation was to find the optimum parametric combinations for improving the fabric quality in a dyeing process. A rotatable central composite design from response surface methodology (RSM) is used for design the experiment. Three main process parameters are chosen as input (namely Fabric heating temperature, Peroxide dosing time 1, Peroxide dosing time 2. The obtained results and various interactions suggest the following conclusion points:

- $\quad$ Fabric heating temperature, peroxide dosing time 1 and peroxide dosing time 2 are having the major influence on the quality of fabric GSM and fabric width.

- On detailed observation of results and interaction it can be concluded that the optimum parametric combinations for achieving the required quality of fabric i.e. Fabric weight $150 \mathrm{GSM}$ and fabric width $180 \mathrm{~cm}$ is very much reachable at the identified parametric combinations i.e. Fabric heating temperature value equals to $90^{\circ} \mathrm{C}$, Peroxide dosing 1 for 5 minutes and peroxide dosing 2 for 7.5 minutes.

- $\quad$ From the experimentation and results it is evident that the quality of the fabric is enhanced significantly by using the identified parametric combination. 


\section{Acknowledgement}

Author is highly acknowledged towards the Maral Overseas Ltd, Khalghat, Khargone (M.P) India for allowing us to use their facility of Fabric Dyeing Setup at their plant. The support staff at MOL are very helpful and supportive especially Mr. A K Rai, AGM (Operations and Mechanical maintenance department) at MOL.

\section{References}

[1]. Najafi et al. (2009) "One bath method dyeing of polyester/cotton blend fabric with sulphatoethylsulphonyl disperse/reactive dyes treatment by chitin biopolymer" African Journal of Biotechnology Vol. 8 (6), pp. 1127-1135.

[2]. Murugesh B. K. and Selvadass. M (2013) "Influence of Wet Processing on Properties of Single Jersey Knitted Fabrics" International Journal of Fiber and Textile Research 2013; 3(1): 18-30, ISSN 2277-7156.

[3]. Saha et al. (2013) "Comparative study on Garments dyeing process and Fabric dyeing process on various parameters (PH, M: L, softener etc)" International Journal of Modern Engineering Research (IJMER), Vol. 3, Issue. 4, Jul - Aug. 2013, ISSN: 22496645, pp-2434-2441.

[4]. Syed et al. (2013) "Dyeing of Organic Cotton Fabric using Conventional and Ultrasonic Exhaust Dyeing Method" Mehran University Research Journal of Engineering \& Technology, Volume 32, No. 2, April, 2013, ISSN 0254-7821.

[5]. Tepparin et al. (2012) "Dyeing of Cotton, Bombyx Mori and Eri Silk Fabrics with the Natural Dye Extracted from Tamarind Seed" International Journal of Bioscience, Biochemistry and Bioinformatics, Vol. 2, No. 3, May 2012.

[6]. Kan and Law (2012) "Effect of Reactive Dyeing and cellulase Treatment on the pilling properties of Cotton Knitted Fabric" International Conference: Textiles \& Fashion 2012, Bangkok Thailand.

[7]. Chowdhury et al. (2009) "Process for Level Dyeing of 100\% Cotton knit Fabrics with reactive Dye" j. innov.dev.strategy. 3(4): $1-8$ 